\title{
PARÍS COMO TROYA, ORIENTE COMO ÍTACA. MAYO DEL 68 EN EL CAMINO DEL CORAZÓN DE FERNANDO SÁNCHEZ DRAGÓ \\ PARIS AS TROY, ORIENT AS ITHACA. MAY 1968 IN EL CAMINO DEL CORAZÓN BY FERNANDO SÁNCHEZ DRAGÓ
}

\author{
FERNANDO GONZÁLEZ GARCÍA \\ Universidad de Valladolid
}

A Ricardo Martín de la Guardia

\begin{abstract}
Resumen
La revuelta de Mayo del 68 en Francia ha sido un tema muy presente en la producción literaria de varios autores españoles contemporáneos. En este trabajo, se estudia el impacto de dicho suceso en la vida, la obra y el pensamiento del escritor Fernando Sánchez Dragó, fundamentalmente a través de su novela El camino del corazón (1990), así como de otros de sus libros, textos y declaraciones públicas. El eje central del artículo es el tránsito del autor, como si de un Ulises moderno se tratase, desde un marxismo heterodoxo hacia un esencialismo místico; unido al papel que juega la literatura en esta conversión ideológica. Palabras Clave: Viaje del héroe, narrativa española, movimiento jipi, misticismo.
\end{abstract}

\section{AbSTRACT}

The May 1968's revolt in France has been a very frequent topic in the literary production of many contemporary Spanish authors. What this work studies is the impact produced by that event on the life, work and thought of the writer Fernando Sánchez Dragó, which is mainly done through his novel El camino del corazón (1990) and also with other of his books, texts and public statements. The central axis of the article is the author's transition, like he was a modern Ulysses, from a heterodox Marxism to a mystic essentialism; linked to the role played by literature during this ideological conversion. KeYwords: The Hero's Journey, Spanish narrative, hippie movement, mysticism.

\footnotetext{
* Recibido: 15-07-2020. Aceptado: 12-08-2020.
} 


\section{El TRÁNSITO BIOGRÁfico}

Fernando Sánchez Dragó, nacido en Madrid el 2 de octubre de 1936 (84 años de edad), es un intelectual español que cuenta en su haber con una vastísima lista de profesiones y etiquetas que le han sido adjudicadas con los años: filólogo, profesor, columnista, novelista, presentador de televisión, comentarista de radio, pensador, místico... Aunque él sólo admita tres, ninguna de ellas presente en la enumeración que he hecho, ni siquiera la de «intelectual». Se define a sí mismo como «lector, escritor y viajero ${ }^{1}$, exclusivamente. No obstante, como tantas veces ha señalado, él es un viajero, no un «turista», concepto que dice despreciar profundamente ${ }^{2}$. Este matiz ya nos da una idea de que se trata de un intelectual, aunque él lo niegue, bastante singular.

Hijo de Fernando Sánchez Monreal y Elena Dragó Carratalá, casados el 14 de enero de 1935 en el oratorio de los Padres Antonios ${ }^{3}$, su nacimiento no se produjo en las mejores circunstancias familiares. Aproximadamente un mes antes, al estallar la Guerra Civil, su padre, periodista de $L a V o z$, fue fusilado en Burgos por las tropas franquistas acusado de «marxista» 4 ; a pesar de que según su hijo era: «un hombre de derechas, del partido de Maura ${ }^{5}$. Esta fatalidad no le impidió, eso sí, tener un gran interés por la cultura desde bien pequeño, asegurando que aprendió a leer a los trescuatro años ${ }^{6}$.

Sería así como, fruto de su temprana iniciación en la lectura, empezó a prender en el pequeño Fernando la llama de su futura vocación como escritor. De hecho, de acuerdo con el testimonio de Sánchez Dragó, habrían sido esas lecturas de niñez las que acabaron moldeando su imaginario literario. «Toda la lectura se forja en la infancia $\mathrm{y}$, desde ese punto de vista, las bibliotecas claves en mi vida son las de mi infancia y adolescencia» ${ }^{7}$.

\footnotetext{
${ }^{1}$ SÁnchez Dragó, F., «La Biblioteca de... Fernando Sánchez Dragó», YouTube.com (2014). Disponible en: https://www.youtube.com/watch?v=-i0AVZM3zTU [Consultado 13-07-2020].

${ }^{2}$ SÁNCHEZ Dragó, F., «Turismo y misantropía», ElMundo.es (2 de septiembre de 2018). Disponible en: https:// www.elmundo.es/opinion/2018/09/02/5b8a9118468aeb510f8b45dc.html [Consultado 13-07-2020].
}

${ }^{3}$ ANónimo, «Boda de un periodista», Heraldo de Madrid (15 de enero de 1935). Disponible en: http:// hemerotecadigital.bne.es/issue.vm?id=0001075968\&search=\&lang=es [Consultado 12-07-2020].

${ }^{4}$ Sánchez Dragó no conoció los verdaderos detalles sobre la muerte de su padre hasta 1956, cuando se encontraba detenido por motivos políticos y el comisario franquista Roberto Conesa se lo hizo saber con intención de humillarle. Este incidente fue el origen de su novela Muertes paralelas, sobre Sánchez Monreal y José Antonio Primo de Rivera (SÁnchez Dragó, F., Muertes paralelas, Barcelona, Planeta, 2006).

${ }^{5}$ CRUZ, J., «Entrevista: Fernando Sánchez Dragó | Escritor "Ahora soy el padre de mi padre”», ElPaís.com (19 de julio de 2006). Disponible en: https://elpais.com/diario/2006/07/19/cultura/1153260002_850215. html [Consultado 13-07-2020].

${ }^{6}$ SÁNChez Dragó, F., «Estoy hasta los huevos de ser Dragó», YouTube.com (2016). Disponible en: https:// www.youtube.com/watch?v=GNrdFR1jTp4 [Consultado 12-07-2020].

${ }^{7}$ SÁNCHEZ DraGó, F., «"Las bibliotecas claves en mi vida son la de mi infancia y adolescencia”», Mi biblioteca: 
Gracias a los esfuerzos de su madre, que impartía clases particulares de francés para mantener a la familia, Fernando pudo educarse en uno de los mejores centros de la capital por aquel entonces, el Colegio Nuestra Señora del Pilar. Una institución de élite conocida por su lema, tomado del Evangelio de Juan: «La verdad os hará libres» (Jn, 8: 32); aforismo que caló mucho en el carácter del pequeño Fernando ${ }^{8}$. El escritor siempre ha tenido buenas palabras para su antiguo lugar de estudios, al que se ha referido como: «Extraordinariamente liberal, a pesar de que era, y es, un colegio religioso» ${ }^{9}$, añadiendo que la formación recibida durante el bachillerato fue «extraordinaria» ${ }^{10}$. Gracias a ella, y por recomendación del director D. Victorino Alegre a su madre, pudo estudiar Filosofía y Letras en la universidad. Una elección extraña para un varón en aquellos años.

Ya en los estudios superiores, Sánchez Dragó cursó, entre los años 1954 y 1959, la licenciatura en Filología Románica en la Universidad de Madrid con gran éxito académico. Sin embargo, su paso por la facultad no estuvo exento de dificultades de otro tipo. En julio de 1955 se hizo miembro (en la clandestinidad, por supuesto) del PCE, aunque según dice no por convencimiento ideológico real, sino por un deseo de correr aventuras. «Me embarqué en la única aventura que se podía correr en aquellos años: el antifranquismo»; y aclara: «Yo nunca fui comunista. A mí dentro del Partido Comunista me llamaban 'maxista-hemingwayano' o 'marxista-vitalista'»11.

Pero ese comunismo no-convencido no le impidió ser detenido hasta cinco veces por la policía de la dictadura. La primera de ellas fue durante el motín antifranquista de 1956, surgido a raíz de la prohibición del Congreso Universitario de Escritores Jóvenes para conmemorar la muerte de Ortega y Gasset un año antes. Y, poco después de su salida, regresó de nuevo a la prisión de Carabanchel por motivos políticos en 1958, procesado por el Código de Justicia Militar. Entre sus compañeros en la cárcel se encontrarían personalidades como Javier Muguerza, Javier Pradera, Enrique Múgica, José María Ruiz Gallardón, Miguel Sánchez Mazas, Ramón Tamames... ${ }^{12}$ : «Todos los

La revista del mundo bibliotecario, 11 (2007), p. 115.

${ }^{8}$ SÁnchez Dragó, F., «Estoy hasta los huevos de ser Dragó», ob. cit.

${ }^{9}$ SÁnchez DraGó, F., «Seis Mujeres Sin Piedad | Fernando Sánchez Dragó», YouTube.com (2017). Disponible en: https://www.youtube.com/watch?v=6ycfuBn6Vd8\&t=268s [Consultado 13-07-2020].

${ }^{10}$ Un dato llamativo sobre este centro es que hacia 1950, como afirman sus exalumnos, no se enseñaba Formación del espíritu nacional y tenían plena libertad para leer a escritores de todo tipo (SÁNCHEz DRAGó, F., «Luis María Ansón: “La educación no se plegaba a la Dictadura”- Salvados», YouTube.com (2015). Disponible en: https://www.youtube.com/watch?v=Bl5epKVbdHk [Consultado 13-07-2020].

${ }^{11}$ Sainz Borgo, K., «Los 80 años de Fernando Sánchez Dragó, “Los enemigos me alimentan, los insultos me divierten"», Vozpópuli.com (28 de septiembre de 2016). Disponible en: https://www.vozpopuli.com/alta voz/cultura/Fernando-Sanchez-Drago-alimentan-divierten_0_957804841.html [Consultado 13-07-2020].

${ }^{12}$ GARCíA, R., «Los protagonistas de febrero del 56 rememoran la revuelta estudiantil», ElPaís.com (23 de febrero de 2006). Disponible en: https://elpais.com/diario/2006/02/23/cultura/1140649203_850215. 
hijos de los vencedores» ${ }^{13}$, a la vez que destacados militantes comunistas durante el franquismo.

Finalmente, Sánchez Dragó y sus compinches saldrían a la calle en octubre del mismo año, gracias al indulto concedido con motivo de la muerte de Pío XII. Pero a pesar de lo dramático que pudiera parecer este hecho, Dragó, en su habitual vitalismo, confiesa que recibió un trato fabuloso en la cárcel. En primer lugar, porque al principio contó con la protección de su tío, Joaquín Ruiz-Giménez, Ministro de Educación saliente en 1956. Y, en lo fundamental, porque: «Para nosotros, los estudiantes detenidos, hijos de los vencedores mayormente, ir a la cárcel de Carabanchel era como ir a un colegio mayor. Teníamos todos los libros que queríamos, nos daban vino...» ${ }^{14}$.

Enlazado con esto, Sánchez Dragó también ha reiterado que, frente a la visión que se tiene hoy acerca del movimiento antifranquista: «Éramos cuatro gatos. Era imposible convencer a la gente, estaba todo el mundo en aquella época encantado con Franco» ${ }^{15}$.

Tras terminar su licenciatura en Filología Románica en 1959, Dragó inició la de Lenguas Modernas, en la especialidad de italiano; doctorándose a la vez en Letras por su alma mater con una tesis sobre las Comedias Bárbaras de Valle-Inclán entre 1960 y 1962. Eso le permitiría trabajar poco después, durante los años de 1964 y 1966, como lector de lengua y literatura españolas en la Universidad de Chieti-Pescara (Abruzos, Italia) ${ }^{16}$.

En 1966 se produce una experiencia crucial en la vida de Sánchez Dragó, un hito en su biografía. Será en ese año cuando emprenda un pausado viaje hacia el lejano Oriente; hacia Tokio, pasando antes, como es obligado, por los territorios de Turquía, Persia, Afganistán, Pakistán y, sobre todo, La India. Precisamente, fue al llegar a suelo indio cuando, pletórico, exclamó: «iEsta es mi tierra!» ${ }^{17}$, fascinado por el hachís y el jipismo que descubrió allí. A partir de entonces, Dragó se convertiría en un ferviente seguidor del movimiento libertino, el chamanismo y la experimentación con las drogas.

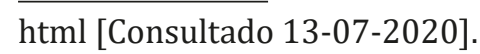

${ }^{13}$ SÁNCHEz DraGó, F., «Los antifranquistas en época de Franco», YouTube.com (2015). Disponible en: https:// www.youtube.com/ watch?v=g_4TSazJxyM [Consultado 13-07-2020].

${ }^{14}$ SÁNCHEZ Dragó, F., «Los antifranquistas en época de Franco», ob. cit.

${ }^{15}$ SÁnchez Dragó, F., «Los antifranquistas en época de Franco», ob. cit.

${ }^{16}$ SÁnchez DraGó, F., «Vida y currículum», Sanchezdrago.com (2020). Disponible en: https://www. sanchezdrago.com/vida-curriculum/ [Consultado 13-07-2020].

${ }^{17}$ GonzÁLEZ, M., «Aquellos rebeldes: La versión española», ElMundo.es (8 de febrero de 2009). Disponible en: https://www.elmundo.es/suplementos/magazine/2009/489/1233748029.html [Consultado 13-072020]. 
En concreto, la fecha clave a juicio del escritor, y corroborada por los estudiosos de su pensamiento, fue el mes de marzo de 1967, cuando llega al noreste de La India, y de ahí a Nepal. Según Aláez Serrano: «Un día de marzo de 1967 sufre una experiencia de conversión en Benarés mientras contempla el Ganges, que le transforma en el hombre religioso que ya nunca dejará de ser» ${ }^{18}$. Es aquí cuando se empieza a ver una, todavía incipiente, variación ideológica en Sánchez Dragó respecto a la versión particular de comunismo que había defendido durante sus años en la universidad.

Al paso de unos pocos días, abandona Benarés (Uttar Pradesh, La India) y llegará a Katmandú, la capital nepalí; una de las ciudades de su vida. Sánchez Dragó recuerda hoy, desde la distancia espacial y temporal, su experiencia allí como la de un pionero en tierras desconocidas: "Yo llegué a Katmandú en marzo de 1967. No había ni un solo hippie. De hecho, durante varios años yo fui, junto a un tal Pepe, con el que nunca llegué a coincidir, [...] los dos únicos hippies que había en todo aquello» ${ }^{19}$.

Algo más de un año después de esa experiencia llegó Mayo del 68, cuando el polvorín saltó por los aires. Pero Sánchez Dragó, que había viajado varias veces a París años antes, no vivió el Mayo francés en primera persona porque se encontraba bastante lejos geográficamente hablando. Existe cierta confusión sobre el lugar exacto donde estuvo Dragó en dicho mes, ya que según declaró en una entrevista en 2009 para el diario El Mundo: «Mientras en aquel mayo de París andaban revolucionados, yo montaba mi marimorena particular en un cuchitril infecto de Taiwan donde, tras una trompa, Caterina y yo concebimos a nuestra hija Ayanta» ${ }^{20}$. Sin embargo, en una reciente entrevista en 2018 con la periodista Nuria Richart, de Libertad Digital, dijo: «Corre por ahí la leyenda de que yo fui poco menos que el que levantó los adoquines delante de la Sorbona (risas). ¡No!, a mí el Mayo francés estrictamente me pilla en Hong Kong. Más lejos imposible» ${ }^{21}$.

Después de analizar dichos testimonios, y al cotejarlos con la trayectoria vital del escritor (que figura detallada en su página web oficial), parece ser que en 1968 Sánchez Dragó fue profesor de lengua y cultura españolas en diversas instituciones educativas de Japón; entre ellas la Gaigo Daigaku, la Universidad Imperial de Tokio o la Escuela Diplomática del Ministerio de Asuntos Exteriores, lo que coincide con su afirmación de que se encontraba en el extremo Oriente durante el Mayo francés. Teniendo en

\footnotetext{
${ }^{18}$ Aláez Serrano, F. J., El pensamiento religioso de Fernando Sánchez Dragó, Francisco Díez de Velasco Abellán (dir.), Universidad Complutense de Madrid, 2016, p. 594.

${ }^{19}$ SÁnchez Dragó, F., «Dragó y Mayo del 68: la "progredumbre” y el Partido del Orgasmo Esmerado», YouTube. com (2018) Disponible en: https://www.youtube.com/watch?v=y_bhgFNNjxY [Consultado 12-07-2020].

${ }^{20}$ GonZÁLEZ, M., «Aquellos rebeldes: La versión española», ob. cit.

${ }^{21}$ SánCHEZ DraGó, F., «Dragó y Mayo del 68: la "progredumbre”...», ob. cit.
} 
cuenta que finalizó su trabajo hacia marzo-abril, y que se sabe que después viajó al otro lado del Mar de la China Oriental22, resulta verosímil que el punto álgido de las protestas ocurriese cuando el escritor estaba en Hong Kong; pero que, días después, se desplazase a la isla de Taiwán. Ello también encajaría con la fecha de nacimiento de su hija Ayanta Barilli, el 17 de febrero de 1969, que hubo de ser concebida hacia el mes de junio de 1968.

A pesar de la distancia geográfica, sí que existía una clara cercanía de espíritu entre Sánchez Dragó y Mayo del 68. Como él mismo dice: «Es verdad que yo... hombre, yo había estado en todo aquel cotarro, en todos aquellos ajos» ${ }^{23}$. Y a eso se añade que unos meses más tarde, al regresar a Katmandú, se reencontró con algunos de sus antiguos compañeros de barricada; con otros hippies como él. «Dos meses después, aquello estaba negro de gente que venía del Mayo francés. Algunos de ellos eran amigos míos que habían colaborado en todo aquello. Igual que yo antes, durante y después lo hice ${ }^{24}$. No obstante, la opinión que tiene hoy Dragó sobre Mayo dista mucho de la que defendía entonces.

\section{EL TRÁNSITO LITERARIO}

El texto por excelencia en el que Sánchez Dragó explica en detalle sus vivencias inmediatamente posteriores a Mayo del 68, acompañadas de su visión sobre la revuelta, es su novela autobiográfica El camino del corazón (1990), ambientada en el bienio 1968-1969. En ella, narra sus viajes por Oriente de forma eminentemente lírica, ficticia; lo que hace que la obra resulte de interés tanto desde el punto de vista de la crítica literaria como desde un enfoque ideológico, y que por tanto merezca un análisis pormenorizado. Labor en la que se ha pretendido estudiar tanto la intencionalidad de la obra como sus distintas influencias narrativas, y que toma como soporte teórico principal la noción del Viaje del héroe, desarrollada por el académico estadounidense Joseph Campbell (1904-1987) ${ }^{25}$. Una vía que cuenta con varios precedentes dentro de la investigación filológica ${ }^{26}$.

\footnotetext{
${ }^{22}$ Aláez Serrano, F. J., El pensamiento religioso de Fernando Sánchez Dragó, ob. cit., pp. 92-93.

${ }^{23}$ SÁnchez Dragó, F., «Dragó y Mayo del 68: la "progredumbre”...», ob. cit.

${ }^{24}$ SÁnchez Dragó, F., «Dragó y Mayo del 68: la "progredumbre”...», ob. cit.

${ }^{25}$ Según sostuvo Campbell: «La aventura mitológica del héroe es la magnificación de la fórmula representada en los ritos de iniciación: separación-iniciación-retorno» (CAMPBELL, J., El héroe de las mil caras. Psicoanálisis del mito, México D.F., Fondo de Cultura Económica, 1972, p. 25).

${ }^{26}$ JIMÉNEZ ARIZA, C., «Sobre mitos antiguos y héroes modernos: Una relectura de La Historia Interminable a partir de El héroe de las mil caras», Álabe: Revista de Investigación sobre Lectura y Escritura, 8 (2013). 
La travesía oriental que Sánchez Dragó cuenta en su libro comienza en la ciudad de Madrid, pasando de allí a Zúrich, Estambul, Erzurum, Bombay, Katmandú, Karachi, Singapur, Yakarta, Denpasar, Saigón, Phnom Penh, Kornak, Delhi, Kabul, Kandahar y de vuelta a la capital española. Retrocediendo al principio, la novela se inicia con la descripción de la decoración psicodélica de un piso madrileño repleto de pinturas, vasijas, fotografías, botellas de licores extraños, máscaras tribales, ídolos de rostro desencajado, talismanes, cojines, espejos, carteles taurinos, revistas antiguas...: «Todo el ajuar, la cacharrería, la quincalla de los restos de un naufragio. Y, naturalmente, discos y libros» ${ }^{27}$. Un ambiente plenamente sesentayochista (o más bien post-sesentayochista).

Una mujer llamada Cristina (que no es sino el trasunto literario de la segunda esposa del escritor, la italiana Caterina Barilli, llevado a la ficción) pregunta a su novio, de nombre Dionisio (alter ego de Sánchez Dragó), si es cierto que piensa marcharse de la ciudad. Se responde a sí misma: «Claro que va a marcharse. Casi todos nuestros amigos lo han hecho ya o aseguran que están a punto de hacerlo. Es la llamada de la selva [...] Los tantanes empezaron a sonar en junio» ${ }^{28}$.

Pero ¿qué había detrás de esta decisión? ¿Qué es lo que lleva a un hombre con una vida apacible en la capital de España a hacer las maletas y emprender esa especie de huida a ninguna parte? Mayo del 68, la derrota de los rebeldes en París; de quienes habían leído, como él, a Jean-Paul Sartre, Herbert Marcuse, Guy Debord, etc.:

La batalla de París -lo que los periódicos del mundo entero llamaban estúpidamente el mayo francés- se había perdido y tras ella, y por su cauce, todos nuestros sueños flotaban a la deriva, pero aún teníamos la posibilidad de huir de la chamusquina por la escalera de incendios: los jipis -la otra cara de la Gran Moneda- andaban ya por Oriente, nos enviaban desde allí su mensaje de sosiego y poco a poco se convertían en carne de leyenda. Lo más sensato era, efectivamente, salir en su busca para encontrar otro centro de gravedad que nos sacara del desbarajuste reinante ${ }^{29}$

Ante la frustración de no haber podido llevar a la imaginación al poder, al darse cuenta de que no se pudo pedir lo imposible atrincherados en el Barrio Latino, quienes, como Sánchez Dragó, pertenecían al ambiente cultural de la izquierda marxista más ecléctica (influido en su caso por la lectura de autores más heterodoxos como Sigmund Freud, Erich Fromm o Albert Camus) decidieron dedicarse a explorar. Explorar tanto otros territorios como a sí mismos. La reflexión era en cierta medida lógica: «¿Por qué no

\footnotetext{
${ }^{27}$ SÁnchez Dragó, F., El camino del corazón, Barcelona, Planeta, 1990, p. 11.

${ }^{28}$ SÁnchez Dragó, F., El camino del corazón, ob. cit., p. 12.

${ }^{29}$ SÁnchez Dragó, F., El camino del corazón, ob. cit., p. 13.
} 
librarnos de las agujetas de la revolución frustrada poniéndonos a rastrear las huellas del paraíso -de otro paraíso- en los territorios vírgenes eternamente olvidados?» ${ }^{30}$.

Dionisio, en un tono optimista propio del autor, asegura a Cristina que, según ha oído, en Asia el dinero no es necesario para sobrevivir, que las gentes de allí son muy agradables y abiertas, que los templos budistas acogen a los viajeros, que hay una espiritualidad más natural, que la autoridad no existe y que es fácil conseguir sustancias psicotrópicas con las que explorar mundos paralelos. Cristina, en un tono mucho más realista y jugando con la metáfora del calor de mayo-junio y el frío invernal le contesta: «De acuerdo en todo, hermanitos de apuestas locas y de inútiles insurrecciones, pero sucede que ya no estamos en junio, sino en diciembre» ${ }^{31}$. Ya no es tiempo de utopías.

La queja de Cristina es bastante prolija. Ha madurado y se ha vuelto una mujer consciente de las circunstancias, y por tanto sólo quiere estabilidad en su vida. Dice a Dionisio que ha vuelto a matricularse en Letras en la universidad; que está harta de proyectos que no conducen a ninguna parte, de vaivenes, de vivir a la intemperie como los vagabundos, de tantos piojos, de la mugre, de retrasar el comienzo de una novela que está deseando escribir, de sobresaltos, de ocultar en su casa a anarquistas prófugos de la justicia, de dar de comer a tanto gorrón marxista, de emborracharse por las noches con alcohol de garrafón, de sentir que huye hacia el vacío, de disimular sus celos, de ese amor sin amor que practican los hippies y de los excesos sexuales a los que se ve obligada sólo para cumplir las expectativas del esnobismo que, hipócritamente, predican.

Dionisio ya ha tomado su decisión. Ambiciona ir a Oriente, la tierra prometida de los libertinos. Frente a esta actitud tan atrevida, Cristina representa lo contrario; no quiere marchar a ninguna parte, lo que busca es tranquilidad, que es lo que su cuerpo le pide. Ha dejado de ser una joven crédula para convertirse en una mujer madura (en una Penélope moderna). Ella representa como nadie el desengaño de la juventud europea con la política.

Desde su punto de vista, los dos necesitan un paréntesis en su relación. Ella es su «compañera» (los hippies se oponen al concepto monógamo de «novia»), le quiere y no le va a reprochar nada si se va de Madrid una temporada, porque es consciente de que ambos necesitan un respiro para airear sus vidas; además, se ha quedado embarazada. Le da permiso para marcharse y Dionisio acepta, prometiendo volver con ella a su regreso ${ }^{32}$.

\footnotetext{
${ }^{30}$ SÁNCHEZ DraGó, F., El camino del corazón, ob. cit., p. 13.

${ }^{31}$ SÁnchez DraGó, F., El camino del corazón, ob. cit., p. 13.

${ }^{32}$ Este pasaje correspondería a lo que Campbell denominó: «la llamada de la aventura», o también «el 
La primera parada en el viaje de Sánchez Dragó, metamorfoseado aquí en Dionisio, será la ciudad alpina de Zúrich, desde donde se desplazará a Estambul, la puerta de entrada a Oriente. Una vez allí dirá: «Estoy huyendo de Europa para descubrir Asia» ${ }^{33}$.

Paradójicamente, es al llegar a Asia cuando Dionisio empieza a recordar Europa, y a su querida Cristina. Llevan cinco años de relación desde el día en que se conocieron en París (no es casualidad); en aquel París bohemio de principios de la década de 1960. Dionisio piensa: «La culpa fue de París, de un amigo común, de un café de artistas, de una tertulia ácrata, de un semisótano, de una quimera compartida, de un arrebato de complicidad ideológica y fisiológica ${ }^{34}$. Las reminiscencias al mundo cultural previo a Mayo del 68 resultan más que evidentes en esta parte de la obra.

Mientras, desde Madrid, Cristina empieza a notar los efectos de la marcha de Dionisio. Su recuerdo sigue ahí, al igual que Mayo del 68: «Joan Baez, desde los altavoces del tocadiscos, me envía los últimos compases del estribillo de una canción que hasta hace seis meses fue nuestro grito de guerra: We shall overcome...». Por primera vez muestra su nostalgia hacia el Mayo francés y la revolución soñada: «El pulso con las lágrimas se resuelve en una sonrisa a mi favor. No nos moverán, ronroneo. $\mathrm{Ni}$ Franco ni Carrillo / no nos moverán. Igual que el pino en la ladera» ${ }^{35}$. Aunque admite que no es cierto, les movieron; todo aquello quedó atrás. De nuevo se ve el dolor por una batalla perdida, un símil con el que Dragó juega en repetidas ocasiones durante la novela.

Pero Dionisio ha continuado su viaje. Huyendo de sus recuerdos de Europa, llega a la ciudad de Erzurum, en el noreste de Turquía, desde donde recorrerá en todoterreno las arenas y pedregales de Persia, Afganistán y Pakistán. Será entonces cuando se encuentre con uno de los personajes clave de su viaje, «el Troglodita de Luarca» ${ }^{36}$. Un gigante asturiano en tierras orientales que representa al pintor Guillermo Gutiérrez, amigo del escritor y al que conoció en 1967 cuando era profesor en Tokio ${ }^{37}$.

En una conversación nocturna con «el Troglodita», este dirá a Dionisio que todo el saber práctico que ha aprendido en su vida lo ha conocido en la calle o corriendo

despertar del yo» (CAMPBelL, J., El héroe de las mil caras. Psicoanálisis del mito, ob. cit., pp. 36-37).

${ }^{33}$ SÁNCHEZ DraGó, F., El camino del corazón, ob. cit., p. 17.

${ }^{34}$ SÁNChEz DraGó, F., El camino del corazón, ob. cit., p. 17.

${ }^{35}$ SÁnchez DraGó, F., El camino del corazón, ob. cit., p. 18.

${ }^{36} \mathrm{El}$ «Troglodita» representaría la figura del guía, aquel ser de «irresistible fascinación» que inaugura un nuevo acto en la obra (CAMPBelL, J., El héroe de las mil caras. Psicoanálisis del mito, ob. cit., p. 39).

${ }^{37}$ Aláez Serrano, F. J., El pensamiento religioso de Fernando Sánchez Dragó, ob. cit., p. 92. 
aventuras. Pero nunca en las bibliotecas, ni en el colegio, ni en la universidad; «ni en las tertulias de alto coturno de tus amiguitos de París». Una clara muestra del desprecio de las gentes populares, de los obreros, hacia el intelectualismo marxista francés, a la que la voz poética de Dragó responderá: «Exacto». Desde el punto de vista de Dionisio, él ha aprendido de la revuelta de París, porque las revoluciones frustradas «no sólo nos gustan y nos divierten, sino que además nos instruyen y nos aleccionan $»^{38}$.

Entre abril y mayo Dionisio llega al Himalaya, a Katmandú, en la camioneta de un sikh. Allí entablará contacto con un grupo de hippies europeos, norteamericanos y australianos. El ambiente que se respiraba en la ciudad era muy particular. Un lugar profundamentemístico alquehabíanllegadocentenares deoccidentales queescuchaban canciones de los Beatles en sus cintas magnetofónicas de origen hongkonés, fumaban hachís, hablaban entre ellos, se reían, dejaban volar la imaginación y frecuentaban los lúgubres burdeles clandestinos de la capital nepalí. Allí Dionisio se sentía como en casa; formaba parte de una fraternidad voluntaria, de la camaradería libertina.

En un mundo donde todo va más despacio como es Oriente, donde los dragones descansan en un plácido letargo, aparecieron los hippies. «Los tránsfugas del consumo, los nómadas del Milenio, los valedores de la última utopía, el anverso de la pereza que por todas partes nos rodeaba o, mejor aún, los santos inocentes que por culpa de su ingenuidad se van derechitos al infierno» ${ }^{39}$. El vicio y la subversión cultural habían llegado incluso al Himalaya. Pensaban que escandalizarían a alguien, pero era todo lo contrario; quienes reían eran los nepalíes. «Por supuesto, seguían allí, entre divertidos y sorprendidos $»^{40}$ ante el hervidero de jipismo en que se había convertido su ciudad ${ }^{41}$.

Será en Katmandú, en compañía de los hippies, cuando Dionisio, o sea Sánchez Dragó, experimente su primer «bautismo psicodélico», justo al día siguiente de llegar. Su primera calada de hachís fue en un local tétrico lleno de anglosajones libertinos. Al rato, notará una sensación extraña que le obligó a salir a la calle para respirar aire puro. Entonces se abrió, tal como asegura en el libro, una brecha en el espacio-tiempo que le hizo estar en trance durante un total de seis horas. Dionisio describe la experiencia

\footnotetext{
${ }^{38}$ SÁNCHEz DraGó, F., El camino del corazón, ob. cit., pp. 48-49.

${ }^{39}$ SÁNChEz DrAGó, F., El camino del corazón, ob. cit., pp. 98-99.

${ }^{40}$ SÁNChez Dragó, F., El camino del corazón, ob. cit., p. 101.

${ }^{41}$ Actualmente, Dragó recuerda que ni durante su etapa comunista anterior a Mayo del 68 ni cuando fue hippie posteriormente él y los suyos incomodaron a las gentes conservadoras de Oriente u Occidente. Al revés: «A la derecha le hacíamos gracia, les caíamos bien» (ARJonA D.; SEgurAdo, I., «Rabiosos vs. Renegados. Una pequeña trifulca de estudiantes prendió la chispa y despertó al fantasma...», ElConfidencial.com (29 de abril de 2018). Disponible en: https://www.Elconfidencial .com/cultura/2018-04-29/mayo-68-aniversarioparis-francia_1555453/ [Consultado 14-07-2020]).
} 
como un momento alucinógeno, de «transrealidad» ${ }^{42}$. Ese desdoble en la percepción llevará al español a decir sobre su delirio provocado por la droga: «había permanecido en éxtasis, acunado por el silencio y la soledad sonora de aquel cortile renacentista de la Florencia de los Médicis, por lo menos un siglo largo de antitiempo cósmico» ${ }^{43}$.

Experiencias como estas llevaron a Dionisio a formar en Katmandú, junto a otros hippies del sur de Europa, mayoritariamente italianos, el llamado «grupo latino». Un colectivo informal que no era ni una agrupación de naturistas ni una guerrilla guevarista perdida, sino simplemente una: «juvenil y alborotadora caterva de rebeldes sin causa ${ }^{44}$, atraídos por ese símbolo de libertad que era el Nepal de 1968-1969. Aunque más que sin causa, Dionisio era un hombre que acababa de perder la suya: la revolución social. Él era algo así como un veterano de guerra, un: «ex combatiente del mayo francés» ${ }^{45}$.

Durante todo este tiempo, Dionisio había demostrado que en Oriente, como efectivamente le habían dicho antes de llegar, se podía sobrevivir: «sin necesidad de recurrir al oprobio del trabajo ni de renunciar a los placeres de la pobreza. No en balde se había ganado el título del primer jipi español de Asia» ${ }^{46}$. Distinción que ambicionaba.

Sin embargo, bajo esa aparente satisfacción, había también una sensación de anhelo; Dionisio echaba de menos su patria, España ${ }^{47}$. Al hablar con un pandit hindú, uno de los personajes mejor valorados intelectualmente de la obra, se lamentará de que su país, que hasta entonces había mantenido a salvo su esencia, estuviese: «a punto de perder su alma por culpa de un grupo de traidores empeñados en importar y en imitar las deplorables costumbres de los anglosajones, de los suecos y de los franceses ${ }^{48}$. Un primer indicio de las duras críticas del escritor hacia el globalismo como pensamiento dominante, y que sigue manteniendo a día de hoy. Es aquí cuando se empieza a notar un cambio importante en Dionisio (Dragó) a la hora de entender el mundo.

\footnotetext{
${ }^{42}$ Existe un paralelo literario a este viaje por los confines de la consciencia en la tradición de los sueños de anábasis: «donde el alma se aventura mientras el cuerpo duerme» (RAmos AGUILAR, C., «El viaje como expresión del misticismo en Segundo sueño de Sergio Fernández», Acta Poética, 35 (2014), p. 137).

${ }^{43}$ SÁnchez Dragó, F., El camino del corazón, ob. cit, pp. 103-108.

${ }^{44}$ SÁnchez Dragó, F., El camino del corazón, ob. cit., p. 122.

${ }^{45}$ SÁNChez Dragó, F., El camino del corazón, ob. cit., p. 126.

${ }^{46}$ Sánchez Dragó, F., El camino del corazón, ob. cit., p. 132.

${ }^{47}$ Aquí existe una clara manifestación del sentimiento homérico del vóotos, el deseo del héroe de regresar a su hogar; cuando los conceptos de alma y retorno se funden entre sí. No en vano, la Odisea «se descubre desde el principio como un decir del cierre, o sea, un decir del alma y del retorno» (Míguez BARCIELA, A., «Acerca del comienzo de la “Odisea”», Myrtia: Revista de filología clásica, 26 (2011), p. 13).
}

${ }^{48}$ SÁnCHEz Dragó, F., El camino del corazón, ob. cit., p. 170. 
Con esas ideas rondando su cabeza, el protagonista de la novela llega a la isla de Bali (Indonesia); la tierra que, según él, le enseñó el camino hacia la felicidad. Allí, conocerá a otro personaje determinante, Bruno, también apodado el «Barón Siciliano», que representa al italiano Francesco Bartoli; amigo de Sánchez Dragó desde septiembre de $1968^{49}$. El Barón es un hombre que viaja para conocer las rarezas propias de cada tierra, por eso desprecia a: «esos filósofos baratos que después de hacer el ridículo en las barricadas de París están invadiendo el territorio libre y fantástico de Oriente» ${ }^{50}$. Y, más aún, detesta hasta lo más profundo de su alma que le confundan con uno de ellos. Con alguien como Dionisio, aunque luego verá que él no es un hippie cualquiera.

El siciliano hablará a Dionisio de un autor muy en boga a finales de la década de 1960 y que él no conocía, el estadounidense Timothy Leary (1920-1996); profesor en Berkeley y Harvard, gran experto en los efectos que produce en el organismo la ingesta de LSD y sumo sacerdote del movimiento psicodélico. Sánchez Dragó beberá mucho intelectualmente de Leary, agradeciendo al consumo de drogas el enorme alivio espiritual que supuso para su alma dejar de comprar el periódico ${ }^{51}$.

Más adelante, Dionisio y el Barón tendrán una experiencia psicodélica bastante intensa al probar unos hongos alucinógenos, supuestamente con poderes sobrenaturales, conocidos como los magic mushrooms; setas que harán pasar un mal trago al español. Experimentará una paranoia aguda, alucinaciones con animales, visiones sobre la muerte y la sensación de tener gusanos recorriendo su cara ${ }^{52}$. Un trance que le durará horas ${ }^{53}$.

Tras recuperarse de ese hechizo enteogénico, Dionisio continúa su camino hacia Vietnam, un territorio en guerra en aquel momento. El punto culminante de la novela se producirá nada más llegar a Saigón, donde tendrá dos diálogos que marcarán un antes y un después para el protagonista. Ver lo que de verdad ocurría en Vietnam fue su caída absoluta del caballo: «Una de las mayores costaladas ideológicas de su existencia $»^{54}$.

Hasta contemplar aquel escenario, Dionisio siempre había creído que los marines estadounidenses eran un hatajo de sádicos que mataban por placer personal

\footnotetext{
${ }^{49}$ SÁNCHEz DraGó, F., La del alba sería, Barcelona, Planeta, 1996, pp. 171-172.

${ }^{50}$ SÁNCHEZ DraGó, F., El camino del corazón, ob. cit., p. 192.

${ }^{51}$ SÁnchez DraGó, F., El camino del corazón, ob. cit., p. 194.

${ }^{52}$ SÁnchez DraGó, F., El camino del corazón, ob. cit., pp. 199-214.

${ }^{53}$ Este episodio, unido al posterior regreso, sano y salvo, de Dionisio al mundo terrenal, podría relacionarse con el pasaje mítico del «rescate del mundo exterior». La vuelta del héroe desde las profundidades de sí mismo (CAMPBelL, J., El héroe de las mil caras. Psicoanálisis del mito, ob. cit., pp. 120-126).
}

${ }^{54}$ SÁnchez DraGó, F., El camino del corazón, ob. cit., p. 223. 
a los pobres vietnamitas; era un seguidor convencido de la teoría del buen salvaje de Rousseau. Pero allí se encontró con un tipo que le hizo cambiar diametralmente su pensamiento. Un nada presentable pseudo-corresponsal de guerra argentino de izquierdas, cliente asiduo de los burdeles de la ciudad y que vivía a 1.500km de Saigón. Dormía en un reconfortante hotel de Vientián (Laos), lejos de los peligros de la guerra, mientras utilizaba a un pobre chico vietnamita para que le mandase las noticias de lo que ocurría en la primera línea del frente. Dionisio se referirá a él como: «aquel soberbio ejemplar de impostor cosmopolita ${ }^{55}$.

El argentino, con una sinceridad pasmosa, dirá a Dionisio que la Guerra de Vietnam es un invento, que no ha existido nunca. No es más que un cubo de basura en el que americanos y soviéticos arrojan sus fantasmas particulares. En Saigón, ciudad a la que procura ir sólo muy de vez en cuando, se pueden ver por la calle soldados americanos con prostitutas del brazo, señoras haciendo fotos, restaurantes franceses a los que llegan turistas de Illinois u oficiales vietnamitas vejando a mendigos; en un lugar que aún conserva los restos putrefactos del colonialismo francés. «No busques héroes ni heroínas ni heroicidades, porque no los encontrarás» ${ }^{56}$, concluyó el corresponsal. La gran mentira que era todo aquello acababa de desvelarse ante los ojos de Dionisio.

La montaña de falsedades que Dionisio (Dragó) tuvo perfectamente asumidas durante décadas se derrumbaba. Ahora se sentía asqueado ante tanto embuste, empezando por el de la sacrosanta libertad de prensa, que no era más que: «Una utopía lanzada por los ilusos y un señuelo hábilmente manejado por la hipocresía democrática para lavar los cerebros de sus súbditos». Y peor aún, sentía verdadera repulsión hacia los periodistas, los: «siniestros protagonistas de la historia universal de la infamia» ${ }^{57}$.

El segundo «zarpazo vietnamita» de Dionisio, que removió todavía más su conciencia, fue con un estudiante de Derecho autóctono que había estado en Europa; en Francia, pero que decía haber perdido el tiempo en ella. El joven también conocía España y pensaba que los españoles: «odiaban a Franco, o quizá fingían que lo odiaban ${ }^{58}$. Sobre Vietnam aseguraba que allí no se vivía una guerra civil sino una invasión, tanto por parte de los capitalistas como de los comunistas. Él no era ninguna de las dos cosas, él era un patriota, y como tal detestaba a los traidores que han vendido su tierra a los extranjeros.

\footnotetext{
${ }^{55}$ SÁnchez Dragó, F., El camino del corazón, ob. cit., p. 228.

${ }^{56}$ SÁNCHEz Dragó, F., El camino del corazón, ob. cit., p. 230.

${ }^{57}$ SÁnchez Dragó, F., El camino del corazón, ob. cit., p. 224.

${ }^{58}$ SÁnCHEz Dragó, F., El camino del corazón, ob. cit., p. 235.
} 
Dionisio le pregunta cuál es su ideología y el chico contestará que sólo es budista. Los budistas son hombres libres, los paradigmas y dicotomías occidentales no tienen nada que ver con ellos. Para él, Occidente sufre dos grandes tabúes: Nuestra incapacidad para criticar la democracia y nuestra fe suicida en el progreso científico, que nos llevan a un empeño estúpido por intentar cambiar el mundo y la naturaleza humana ${ }^{59}$.

Frente a esos absurdos el budista afirma: «La igualdad no sólo no es posible, sino que tampoco es deseable», y apostilla: «La caja de Pandora es la revolución francesa $»^{60}$. El diálogo terminará con una frase demoledora contra la injerencia americana y soviética en el mundo: « ¿Conoces alguna forma de colonialismo peor que la tentativa de exportar a la fuerza o con halagos, qué más da, los usos y costumbres de cualquier país a otro que los tiene diferentes? ${ }^{61}$. Este fue el último estoque a la fe agonizante de Dioniso en los ideales de la izquierda y la revolución. Ahora veía a Mayo del 68 como un: «callejón sin salida en el que por culpa del absurdo y demagógico debate abierto sobre el compromiso político se habían encerrado muchos escritores occidentales» ${ }^{62}$. Ya no es el mismo.

La novela acaba con Dionisio volviendo de nuevo a Madrid, donde le espera su hija recién nacida. Pero Cristina ha muerto a causa del parto, Dionisio ha perdido a la mujer que más amaba. Su hija no podrá conocer a su madre, al igual que Sánchez Dragó tampoco conoció a su padre. En memoria del viaje, y de las cartas que sus progenitores se escribían, la niña se llamará María de Kandahar (Ayanta Barilli en la realidad), en honor a la ciudad afgana donde Dionisio recibió una carta con la noticia de su nacimiento. Aun así, en el terreno de la no-ficción, aunque es cierto que la auténtica Caterina Barilli sí tuvo una muerte temprana, esta no falleció hasta nueve años después de que naciera Ayanta. Deceso que se produjo en Roma, no en Madrid ${ }^{63}$.

\footnotetext{
${ }^{59}$ La contraposición que hace aquí Sánchez Dragó entre el corresponsal argentino, que reúne todos los rasgos característicos del antihéroe, frente a la admirable sinceridad del muchacho vietnamita, también podría entenderse como una metáfora del autor sobre un Occidente hipócrita y un Oriente incorrupto.

${ }^{60}$ SÁnchez Dragó, F., El camino del corazón, ob. cit., pp. 240-241.

${ }^{61}$ SÁnchez Dragó, F., El camino del corazón, ob. cit., p. 241.

${ }^{62}$ SÁnCHEz Dragó, F., El camino del corazón, ob. cit., p. 265.

${ }^{63}$ Este modo de culminar la novela reproduce casi al milímetro la descripción que hace Campbell a propósito del retorno del héroe: «¿Cuál es el resultado del pasaje milagroso y del regreso? El campo de batalla es simbólico del campo de la vida, donde cada criatura vive de la muerte de otra» (CAMPBELL, J., El héroe de las mil caras. Psicoanálisis del mito, ob. cit., p. 136).
} 


\section{3. ¿UN ULISES MODERNO?}

En términos generales, El camino del corazón resultó ser una obra bastante bien acogida en nuestro país; tanto por parte del público, con alrededor de ciento veintisiete mil ejemplares vendidos, como de la crítica ${ }^{64}$, quedando finalista del Premio Planeta ${ }^{65}$. Sin embargo, la novela también fue objeto de alguna valoración despiadada como la de Andrés Salom. Un autor que opinaba que la técnica de escritura del libro era «la del collage» y que definió su argumento como: «un amor desvaído entre una Penélope sin túnica que tejer y un Ulises sin historia» ${ }^{66}$. Comentarios que, a mi juicio, no podrían ser más erróneos, ya que la obra de Sánchez Dragó es un buen ejemplo de cómo lograr un equilibrio entre la literatura más canónica y la exploración de nuevos temas.

No resulta difícil ver en la novela, por un lado, la huella de la tradición clásica, cuyos fundamentos fueron descritos por Aristóteles en su Poética ${ }^{67}$, existiendo una cercanía más que evidente entre Dionisio y los héroes clásicos; muy señaladamente el Ulises homérico ${ }^{68}$ (como bien apunta Salom), aunque no en exclusiva. La Troya de Dragó, el desastre del que huye, es Mayo del 68, y la aventura que se nos cuenta es el descreimiento del protagonista de todas sus ideas ilusorias; su salida de la caverna en términos platónicos. El motor narrativo es el viaje cíclico del héroe, en el que Dionisio experimentará desde la nostalgia de su tierra natal hasta la restitución de su vida una

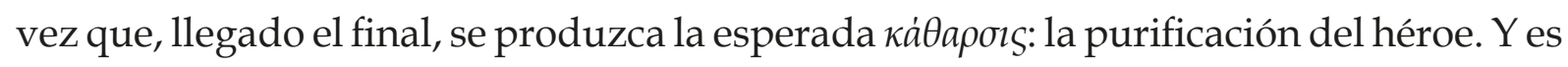
que el viaje puede suponer tanto el origen del conflicto como su medio de salvación ${ }^{69}$.

Del mismo modo, también puede verse una importante deuda con la literatura española, en especial con la idea del «Esperpento» de Valle-Inclán (no en vano este fue el autor al que Sánchez Dragó dedicó su tesis). La razón fundamental que explica dicha influencia es que, si bien Dionisio (Dragó) tiene una parte de héroe clásico, tampoco deja de estar sujeto a su condición de hombre español contemporáneo; lo que le convierte en una especie de Ulises deformado o actualizado ${ }^{70}$. Como explica Valle-

\footnotetext{
${ }^{64}$ MARCo, J., «El camino del corazón», $A B C$ (17 de noviembre de 1990). Disponible en: https://hemeroteca. abc.es /nav/Navigate.exe/hemeroteca/madrid/abc/1990/11/17/064.html [Consultado 14-07-2020].

${ }^{65}$ Aláez Serrano, F. J., El pensamiento religioso de Fernando Sánchez Dragó, ob. cit., p. 226.

${ }^{66}$ SAlom, A., «El camino del corazón de Fernando Sánchez Dragó», Monteagudo: Revista de literatura española, hispanoamericana y teoría de la literatura, 9 (1991), p. 55.

${ }^{67}$ ArIstóteles, Poética, Madrid, Alianza Editorial, 2013.

${ }^{68}$ A propósito de la influencia actual de la Odisea fuera del género narrativo, en poesía (Conde PARRADo, P., «Ecos de Homero en el discurso poético contemporáneo. La Odisea en verso», en Orfeo XXI. Poesía española contemporánea y tradición clásica, Pedro Conde Parrado y Javier García Rodríguez (eds.) Gijón, Llibros del Pexe, 2005, pp. 79-100).

${ }^{69}$ EnCINAS REguero, M. C., «El viaje en la tragedia griega», Cuadernos de filología clásica: Estudios griegos e indoeuropeos, 28 (2018), p. 110.

${ }^{70}$ Sobre la actualización de lo heroico dentro de la narrativa española contemporánea (IBÁÑEz EHRLICH, M.
} 
Inclán de manera célebre en Luces de Bohemia a través de Max Estrella: «Los héroes clásicos reflejados en los espejos cóncavos dan el Esperpento. El sentido trágico de la vida española sólo puede darse con una estética sistemáticamente deformada» ${ }^{71}$ 72. Actualización que también han tratado de hacer otros escritores contemporáneos como Juan Manuel de Prada ${ }^{73}$.

Y también, aunque en un sentido no tan evidente como el de los casos anteriores, en la novela Dragó trata al mismo tiempo de emular, o mejor dicho introducir, a la Beat Generation estadounidense en España; tanto desde el punto de vista estilístico como en su idea del tipo de aventuras que puede vivir el hombre moderno. Lo que iniciaron los Beat (una de las fuentes de las que bebió Mayo del 68, aunque con matices), fue la figura del llamado hipster. Aquel que lo que busca con su éxtasis no es sino: «una sensación de pertenecer a algo ${ }^{74}$, consecuencia de la pérdida de valores a la que había conducido la posguerra en América, y que después desembocaría en los hippies. Jack Kerouac plasma esta idea a la perfección en On the road, al reconocer que: «Aunque tuviera no pocos problemas e incluso Dean pudiera dejarme tirado, como haría más tarde, en cunetas y lechos de enfermo, ¿qué importaba eso? Yo era un joven escritor y quería viajar» ${ }^{75}$.

Una gran síntesis entre tradición y modernidad literaria que convierte a El camino del corazón en una de las publicaciones relativamente recientes en lengua española que mejor ha sabido trasladar hasta el presente el concepto del Viaje del héroe teorizado por Campbell. Idea que se encuentra en buena parte de las obras más veneradas dentro de la literatura occidental, y que Dragó retoma para explicar su cambio de pensamiento.

Ya en la década de 1970, existen otras dos grandes evidencias del viraje ideológico de Sánchez Dragó desde la izquierda revolucionaria hacia lo que se podría denominar un esencialismo místico. Misticismo que él rechazaba calificar como «derechista», pero que a todas luces estaba mucho más cerca de la derecha política que de la izquierda; con la permanencia, eso sí, de su vena libertaria, siempre presente en el escritor.

T., «El concepto de héroe y su desarrollo en la literatura española actual», Céfiro: Enlace hispano cultural y literario, 9 (2009), pp. 35-65).

${ }^{71}$ VAlle-InClán, R. DEL, Luces de Bohemia, Madrid, Espasa-Calpe, 1975, p. 106.

${ }^{72}$ De hecho, el apodo de «Troglodita de Luarca» que Sánchez Dragó emplea para su amigo Guillermo Gutiérrez parece estar tomado de la misma obra. En concreto, aparece en la Escena Cuarta, cuando Don Latino de Hispalis dice a su amigo de aventuras ante la llegada del Sereno: «Max, convídale a una copa. Hay que domesticar a este troglodita asturiano» (VALLE-InCLÁn, R. DEL, Luces de Bohemia, ob. cit., p. 44).

${ }^{73}$ Gómez, M. A., «"Las máscaras del héroe” de Juan Manuel de Prada: una reescritura del esperpento», Anales de la literatura española contemporánea, ALEC, 26 (2001), pp. 115-132.

${ }^{74}$ Clellon Holmes, J., Esta es la Generación Beat. La filosofía de la Generación Beat, León, Universidad de León, 1997, pp. 48-49.

${ }^{75}$ Kerouac, J., En el camino, Barcelona, Anagrama, 2001, p. 19. 
En primer lugar, en 1973, mientras se encontraba en Senegal, Dragó asegura que vivió una experiencia iniciática fallida en la «Isla de las conchas» de Joal-Fadiuth. Un viaje nocturno a la tierra de los muertos en el que sentirá un miedo intenso que le impedirá pisar el lugar y terminar el tránsito, padeciendo extraños sueños de tipo erótico en los que un cangrejo mutilaba sus genitales ${ }^{76}$. Una visión, según afirmaba, con reminiscencias jungianas y que habla de un Sánchez Dragó cada vez más religioso y espiritualista ${ }^{77}$.

Pero aún más significativa fue la publicación, en 1978, de la obra que dio a conocer al escritor: Gárgoris y Habidis. Una historia mágica de España. Un texto que recibió el Premio Nacional de Ensayo ${ }^{78}$ y en el que Sánchez Dragó trató de internarse en el imaginario colectivo hispánico, que a su juicio hunde sus raíces en la prehistoria más remota, para tratar de encontrar la esencia de España. El: «talante crónico perpetuamente actual», inmortal, del pueblo español ${ }^{79}$. En un momento en que, en opinión de Sánchez Dragó, nuestro país se había contagiado del «delirio progresista» ${ }^{80}$, sólo cabía esperar la llegada de un grupo de pensadores libres que despertasen a la nación. Hasta entonces, quedaría la nostalgia de un tiempo en que «todo, y no sólo España, fue mitología» ${ }^{81}$.

\section{Conclusiones}

La noción fundamental que se puede extraer del papel jugado por Mayo del 68 en la novela de Sánchez Dragó es que, efectivamente, el Mayo francés sirve al autor como una Troya moderna; como el arranque de su particular viaje del héroe contemporáneo. Un nuevo modelo de individuo heroico que ya no se enfrenta a los viejos monstruos que atormentaban a los hombres de la Antigüedad, sino al que se le plantean otros desafíos no menos duros. Como explica Campbell: «Donde antes había oscuridad, hoy hay luz; pero también donde había luz hay ahora oscuridad. La

\footnotetext{
${ }^{76}$ Sánchez Dragó relató este viaje iniciático en el programa El sol de medianoche, de Sibila Pironti, en 1990 (SÁnchez Dragó, F., «El viaje iniciático - El sol de medianoche - TVE», YouTube.com (2014). Disponible en: https://www.youtube.com/watch?v=cAh2q9CKLtM\&t=772s [Consultado 14-07-2020]).

${ }_{77}$ Para la influencia del psicólogo suizo Carl Gustav Jung en Sánchez Dragó (AláEz Serrano, F. J., El pensamiento religioso de Fernando Sánchez Dragó, ob. cit., pp. 361-376).

${ }^{78}$ El ensayo de Sánchez Dragó también desató una gran polémica nada más publicarse. A propósito de ella, (BEAumont, J. F., «"Gárgoris y Habidis” es una obra esencialmente provocadora», ElPaís.com (19 de diciembre de 1979). Disponible en: https://elpais.com/diario/1979/12/19/cultura/314406007_850215. html [Consultado 14-07-2020]).

${ }^{79}$ SÁnchez Dragó, F., Gárgoris y Habidis. Una historia mágica de España. I, Los orígenes, Pamplona, Peralta, 1979, pp. 21-24.

${ }^{80}$ SÁnchez Dragó, F., Gárgoris y Habidis. Una historia mágica de España. I, Los orígenes, ob. cit., p. 24.

${ }^{81}$ Sánchez Dragó, F., Gárgoris y Habidis. Una historia mágica de España. I, Los orígenes, ob. cit., p. 49.
} 
hazaña del héroe moderno debe ser la de pretender traer la luz de nuevo a la perdida Atlántida del alma coordinada» ${ }^{82}$.

París es el punto de partida desde donde Sánchez Dragó, oculto bajo la máscara de Dionisio, comienza un camino de purificación en el que irá conociendo el verdadero significado de la vida. Así, sus diferentes encuentros con lo sagrado le permitirán salir del callejón sin salida en que se hallaba tras el derrumbe de los ideales sesentayochistas. Por su parte, Oriente y los fuertes choques que le provocará la realidad vietnamita, camuflada bajo la propaganda de los medios de comunicación, entregados al discurso izquierdista, darán a Dragó una nueva forma de entender la existencia humana. Una vía de escape del nihilismo al que conduce la sociedad de masas y a la vez alternativa al pensamiento marxista. Ya no es aquel devoto ingenuo de una ideología basada en el goce sin límites y la autodestrucción, sino un místico convencido. Un pagano orientalista. Alguien que se ha convertido al esencialismo filosófico, rechazando el existencialismo sartriano.

Y al final, después de tantas peripecias, como en la travesía de Ulises, a Sánchez Dragó le esperan su familia y su hogar. Sobre todo su hija, María de Kandahar (Ayanta), símbolo del regalo que los dioses conceden al héroe tras completar su viaje.

\section{BibLIOGRAFÍA}

Aláez Serrano, F. J., El pensamiento religioso de Fernando Sánchez Dragó, Francisco Díez de Velasco Abellán (dir.), Universidad Complutense de Madrid, 2016.

ANÓNIMO, «Boda de un periodista», Heraldo de Madrid (15 de enero de 1935). Disponible en: http:/ / hemerotecadigital.bne.es/issue.vm?id=0001075968\&search=\&lang=es [Consultado 12-07-2020].

Aristóteles, Poética, Madrid, Alianza Editorial, 2013.

ArjonA, D.; SEGURAdo, I., «Rabiosos vs. Renegados. Una pequeña trifulca de estudiantes prendió la chispa y despertó al fantasma...», ElConfidencial.com (29 de abril de 2018). Disponible en: https://www.Elconfidencial.com/cultura/2018-04-29/ mayo -68-aniversario-paris-francia_1555453/ [Consultado 14-07-2020].

BEAUMONT, J. F., «"Gárgoris y Habidis” es una obra esencialmente provocadora», ElPaís. com (19 de diciembre de 1979). Disponible en: https://elpais.com/diario/ 1979/12/19/cultura/ 314406007_850215.html [Consultado 14-07-2020].

Campbell, J., El héroe de las mil caras. Psicoanálisis del mito, México D.F., Fondo de Cultura Económica, 1972.

Clellon Holmes, J., Esta es la Generación Beat. La filosofía de la Generación Beat, León, Universidad de León, 1997.

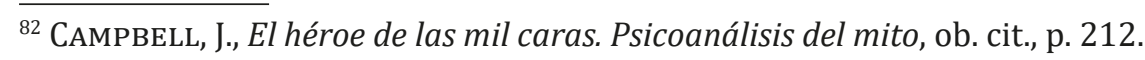


Conde Parrado, P., «Ecos de Homero en el discurso poético contemporáneo. La Odisea en verso», en Orfeo XXI. Poesía española contemporánea y tradición clásica, Pedro Conde Parrado y Javier García Rodríguez (eds.) Gijón, Llibros del Pexe, 2005, pp. 79-100.

Cruz, J., «Entrevista: Fernando Sánchez Dragó | Escritor "Ahora soy el padre de mi padre"», ElPaís.com (19 de julio de 2006). Disponible en: https:/ / elpais.com/ diario/2006/07/19/cultura/1153260002_850215.html] [Consultado 13-072020].

Encinas Reguero, M. C., «El viaje en la tragedia griega», Cuadernos de filología clásica: Estudios griegos e indoeuropeos, 28 (2018), pp. 101-113.

GARCíA, R., «Los protagonistas de febrero del 56 rememoran la revuelta estudiantil», ElPaís.com (23 de febrero de 2006). Disponible en: https:/ / elpais.com/diario/ 2006/02/23/cultura/1140649203_850215.html [Consultado 13-07-2020].

Gómez, M. A., «"Las máscaras del héroe” de Juan Manuel de Prada: una reescritura del esperpento», Anales de la literatura española contemporánea, ALEC, 26 (2001), pp. 115-132.

GONZÁLEZ,M., «Aquellos rebeldes: La versiónespañola»,ElMundo.es(8defebrero de2009). Disponible en: https://www.elmundo.es/suplementos/magazine/2009/ 489/ 1233748029.html [Consultado 13-07-2020].

IBÁÑEZ EHRLICH, M. T., «El concepto de héroe y su desarrollo en la literatura española actual», Céfiro: Enlace hispano cultural y literario, 9 (2009), pp. 35-65.

JimÉNEZ ARIZA, C., «Sobre mitos antiguos y héroes modernos: Una relectura de La Historia Interminable a partir de El héroe de las mil caras», Álabe: Revista de Investigación sobre Lectura y Escritura, 8 (2013).

Kerouac, J., En el camino, Barcelona, Anagrama, 2001.

MARCO,J., «Elcaminodelcorazón»,ABC(17 denoviembrede1990).Disponibleen:https:/ / hemeroteca.abc.es/nav/Navigate.exe/hemeroteca/madrid/abc/1990/11/ 17/064.html [Consultado 14-07-2020].

Míguez Barciela, A., «Acerca del comienzo de la "Odisea" », Myrtia: Revista de filología clásica, 26 (2011), pp. 11-26.

Ramos Aguilar, C., «El viaje como expresión del misticismo en Segundo sueño de Sergio Fernández», Acta Poética, 35 (2014), pp. 137-147.

Sainz Borgo, K., «Los 80 años de Fernando Sánchez Dragó, “Los enemigos me alimentan, los insultos me divierten"», Vozpópuli.com (28 de septiembre de 2016). Disponible en: https://www.vozpopuli.com/altavoz/cultura/ Fernando-Sanchez-Drago-alimentan-divierten_0_957804841.html [Consultado 13-07-2020].

SAlom, A., «El camino del corazón de Fernando Sánchez Dragó», Monteagudo: Revista de literatura española, hispanoamericana y teoría de la literatura, 9 (1991) p. 55.

SÁNCHEz DraGó, F., «Vida y currículum», Sanchezdrago.com (2020). Disponible en: https:/ / www.sanchezdrago.com/vida-curriculum/ [Consultado 13-07-2020]. 
, «Turismo y misantropía», ElMundo.es (2 de septiembre de 2018). Disponible en: https://www.elmundo.es/opinion/2018/09/02/5b8a9118468aeb510f8b45dchtml [Consultado 13-07-2020].

, «Dragó y Mayo del 68: la "progredumbre" y el Partido del Orgasmo

Esmerado», YouTube.com (2018) Disponible en: https:/ / www.youtube.com/

watch?v=y_bhg FNNjxY [Consultado 12-07-2020].

«Seis Mujeres Sin Piedad | Fernando Sánchez Dragó», YouTube.com (2017).

Disponible en: https:/ $/$ www.youtube.com/watch?v=6ycfuBn6Vd8\&t=268s

[Consultado 13-07-2020].

«Estoy hasta los huevos de ser Dragó», YouTube.com (2016). Disponible en:

https://www.youtube.com/watch?v=GNrdFR1jTp4 [Consultado 12-072020].

, «Luis María Ansón: “La educación no se plegaba a la Dictadura”-

Salvados», YouTube.com (2015). Disponible en: https:/ /www.youtube.com/ watch?v=B15ep KVbdHk [Consultado 13-07-2020].

, «Los antifranquistas en época de Franco», YouTube.com (2015). Disponible en: https:/ / www.youtube.com/watch?v=g_4TSazJxyM [Consultado 13-07-2020]. , «La Biblioteca de... Fernando Sánchez Dragó», YouTube.com (2014).

Disponible en: https:/ / www.youtube.com/watch?v=-i0AVZM3zTU

[Consultado 13-07-2020].

, «El viaje iniciático - El sol de medianoche - TVE», YouTube.com (2014).

Disponible en: https:/ / www.youtube.com/watch?v=cAh2q9CKLtM\&t=772s [Consultado 14-07-2020].

«"Las bibliotecas claves en mi vida son la de mi infancia y adolescencia"», Mi biblioteca: La revista del mundo bibliotecario, 11 (2007), pp. 114-116.

, Muertes paralelas, Barcelona, Planeta, 2006.

, La del alba sería, Barcelona, Planeta, 1996.

El camino del corazón, Barcelona, Planeta, 1990.

, Gárgoris y Habidis. Una historia mágica de España. I, Los orígenes, Pamplona, Peralta, 1979.

Valle-InCLÁn, R. DEL, Luces de Bohemia, Madrid, Espasa-Calpe, 1975. 